\title{
Baudelaire e sua resistência irônica ao capitalismo
}

\author{
Baudelaire and his ironic restriction towards capitalism \\ Márcio Seligmann-Silva \\ Universidade de Campinas (UNICAMP) - Campinas - São Paulo - Brasil
}

\begin{abstract}
Resumo: O texto faz uma leitura do poema em prosa de Baudelaire "La fausse monnaie" mostrando que se pode deduzir do poema as figuras paradigmáticas do homo aestheticus e do homo sacer. O primeiro incorpora muitos aspectos daquilo que foi sonhado para o novo homem desde o final do século XVIII por pensadores, como os membros do romantismo alemão Friedrich Schlegel e Novalis. Para eles, o artista estaria no topo da humanidade. A arte curaria as feridas abertas pelo progresso e pela alienação que caracteriza o indivíduo moderno. Por outro lado, o homo sacer é pensado, segundo Agamben, como um resto, uma descarga em forma de carne humana que é rejeitada pela sociedade como meio de se manter a estrutura de poder do soberano. Essa paisagem biopolítica não é estática e tem a sua própria dinâmica. Podemos dizer que um lado da moeda depende da existência do outro lado. O espetáculo da violência, pobreza e miséria é parte de nosso mundo estetizado e não o seu oposto. Nesse sentido, o poema é uma espécie de microcosmo de nosso mundo e de sua nova moneyscape.
\end{abstract}

Palavras-chave: Homo aestheticus; Homo sacer; Estetização da política; Arte e dinheiro

\begin{abstract}
This text takes a reading of a prose-poem by Baudelaire "La fausse monnaie", and shows that the paradigmatic figures of homo aestheticus and homo sacer can be deduced from the poem. The first figure incorporates multiple aspects of what was dreamt by thinkers -such as the members of the German Romanticism Friedrich Schlegel and Novalis - for the new man since the end of the 18th century. For them, the artist would be at the top of humanity. The art would cure the open wounds by the progress and the alienation that characterise the modern individual. On the other hand, according to Agamben, homo sacer is seen like a leftover, a discharge in form of human flesh that is rejected by society as a means of maintaining the structure of the ruler's power. This bio-political landscape is not static and has its own dynamic. It can be said that one side of the coin depends on the existence of the other. The spectacle of violence, poverty and misery is part of our aestheticised world and not its opposite. This being said, the poem is a kind of microcosm of our world and its new moneyscape.
\end{abstract}

Keywords: Homo aestheticus; Homo sacer; Political aesthetics; Art and money

\section{La fausse monnaie}

Comme nous nous éloignions du bureau de tabac, mon ami fit un soigneux triage de sa monnaie; dans la poche gauche de son gilet il glissa de petites pièces d'or; dans la droite, de petites pièces d'argent; dans la poche gauche de sa culotte, une masse de gros sols, et enfin, dans la droite, une pièce d'argent de deux francs qu'il avait particulièrement examinée.

"Singulière et minutieuse répartition!" me dis-je en moi-même.

Nous fîmes la rencontre d'un pauvre qui nous tendit sa casquette en tremblant. - Je ne connais rien de plus inquiétant que l'éloquence muette de ces yeux suppliants, qui contiennent à la fois, pour l'homme sensible qui sait y lire, tant d'humilité, tant de reproches. Il y trouve quelque chose approchant cette profondeur de sentiment compliqué, dans les yeux larmoyants des chiens qu'on fouette.

L'offrande de mon ami fut beaucoup plus considérable que la mienne, et je lui dis: "Vous avez raison; après le plaisir d'être étonné, il n'en est pas de plus grand que celui de causer une surprise. - C'était la pièce fausse", me répondit-il tranquillement, comme pour se justifier de sa prodigalité.

Mais dans mon misérable cerveau, toujours occupé à chercher midi à quatorze heures (de quelle fatigante faculté la nature m'a fait cadeau!), entra soudainement cette idée qu'une pareille conduite, de la part de mon ami, n'était excusable que par le désir de créer un 
événement dans la vie de ce pauvre diable, peut-être même de connaître les conséquences diverses, funestes ou autres, que peut engendrer une pièce fausse dans la main d'un mendiant. Ne pouvait-elle pas se multiplier en pièces vraies? ne pouvait-elle pas aussi le conduire en prison? Un cabaretier, un boulanger, par exemple, allait peut-être le faire arrêter comme faux-monnayeur ou comme propagateur de fausse monnaie. Tout aussi bien la pièce fausse serait peut-être, pour un pauvre petit spéculateur, le germe d'une richesse de quelques jours. Et ainsi ma fantaisie allait son train, prêtant des ailes à l'esprit de mon ami et tirant toutes les déductions possibles de toutes les hypothèses possibles.

Mais celui-ci rompit brusquement ma rêverie en reprenant mes propres paroles: "Oui, vous avez raison; il n'est pas de plaisir plus doux que de surprendre un homme en lui donnant plus qu'il n'espère".

Je le regardai dans le blanc des yeux, et je fus épouvanté de voir que ses yeux brillaient d'une incontestable candeur. Je vis alors clairement qu'il avait voulu faire à la fois la charité et une bonne affaire; gagner quarante sols et le cœur de Dieu; emporter le paradis économiquement; enfin attraper gratis un brevet d'homme charitable. Je lui aurais presque pardonné le désir de la criminelle jouissance dont je le supposais tout à l'heure capable; j'aurais trouvé curieux, singulier, qu'il s'amusât à compromettre les pauvres; mais je ne lui pardonnerai jamais l'ineptie de son calcul. On n'est jamais excusable d'être méchant, mais il y a quelque mérite à savoir qu'on l'est; et le plus irréparable des vices est de faire le mal par bêtise. (BAUDELAIRE, 1975, p. 323s.)

\section{A moeda falsa}

Ao nos afastarmos da tabacaria, meu amigo fez uma separação cuidadosa de suas moedas. No bolso esquerdo do colete, pôs pequenas peças de ouro; no direito, peças de prata; no bolso esquerdo da calça, um punhado de grandes soldos; e finalmente, no direito, uma peça de prata de dois francos, depois de examiná-la atentamente.

- Singular e minuciosa repartição! - disse eu comigo.

Encontramos um pobre que nos estendeu o boné com a mão trêmula. Não conheço nada mais inquietador do que a muda eloquência desses olhos súplices, que encerram a um tempo, para o homem sensível que sabe lê-los, tanto humildade como censuras. Há alguma coisa que se aproxima dessa profundeza de sentimento complicado nos olhos lacrimosos dos cães quando apanham.

A oferenda do meu amigo foi muito mais considerável do que a minha. Por isso, disse-lhe eu:

- Você tem razão: depois do prazer da comoção, não há outro maior do que o de causar uma surpresa.

- Mas, foi a moeda falsa, - respondeu ele, tranquilamente, como para justificar-se de sua prodigalidade.
Então, no meu miserável cérebro, sempre preocupado em achar meio-dia às catorze horas (de que estafante faculdade a natureza me fez presente!), entrou subitamente a ideia de que semelhante conduta, da parte do meu amigo, só era desculpável pelo desejo de criar um acontecimento na vida daquele pobre diabo, ou talvez pelo desejo de conhecer as diversas consequências, funestas e outras, que uma moeda falsa pode suscitar na mão de um mendigo. Não poderia ela multiplicar-se em peças verdadeiras? não poderia também conduzi-lo à prisão? Um taberneiro, um padeiro, por exemplo, talvez mandasse prendê-lo como falsário ou como passador de dinheiro falsificado. Talvez, também, a peça falsa pudesse tornar-se, para um pobre pequeno especulador, o gérmen de uma riqueza de alguns dias. E assim minha fantasia seguia seu curso, emprestando asas ao espírito do meu amigo e tirando todas as deduções possíveis de todas as hipóteses possíveis.

Nisso, ele interrompeu bruscamente o meu sonho, retomando minhas próprias palavras:

- Sim, você tem razão: não há prazer mais doce do que surpreender um homem dando-lhe mais do que ele espera.

Olhei-o fixamente e fiquei admirado de ver que os seus olhos brilhavam com incontestável candura. Vi então, claramente, que ele quisera fazer ao mesmo tempo a caridade e um bom negócio; ganhar quarenta soldos e o coração de Deus; conquistar o paraíso economicamente; enfim, conseguir gratuitamente o título de homem caridoso. Eu quase lhe perdoaria o desejo do criminoso prazer de que doravante o supunha capaz; acharia curioso, singular, que se divertisse em comprometer os pobres; nunca lhe perdoarei, porém, a inépcia do cálculo. Não há desculpa para o perverso, mas tem um certo mérito o que sabe o que é; e o mais irreparável dos vícios é praticar o mal por estupidez. (BAUDELAIRE, 1937, p. 44)

Iniciei este texto com este poema em prosa conhecido e particularmente witty de Baudelaire, o "La fausse monnaie", de 1864, porque acredito encontrar nele alguns temas importantes para tratar da relação crítica entre a esfera estética e a financeira, o objeto que elegi para este texto sobre literatura e resistência. Esta pequena peça trata de um encontro de dois burgueses com um mendigo que pede esmola. Mais do que isto, creio poder ver neste texto uma sofisticada mise en scène de aspectos fundamentais do capitalismo, que o surpreende na sua intersecção com a religião e com um novo estatuto do campo estético. $\mathrm{O}$ narrador da anedota pode ser compreendido como uma espécie de duplicação tanto do autor como do próprio leitor: ele representa uma instância observadora que descreve os fatos e os julga a partir de uma moral judaico-cristã com a qual normalmente os leitores de poesia ainda tendem a concordar, mesmo 150 anos após 
a sua composição. A cena descrita é a de um indivíduo que passa uma falsa moeda como esmola. $\mathrm{O}$ narrador reflete sobre o que poderia acontecer a partir daquele fato. Aquela falsa moeda poderia tanto "multiplicar-se em peças verdadeiras" ("se multiplier en pièces vraies") como, nas mãos de "um pobre pequeno especulador" ("un pauvre petit spéculateur"), tornar-se "o gérmen de uma riqueza de alguns dias" ("le germe d'une richesse de quelques jours") ou, talvez ainda, poderia levar o mendigo para a prisão. O feito é condenado como a tentativa "fazer ao mesmo tempo a caridade e um bom negócio" ("de faire à la fois la charité et une bonne affaire"), ou ainda como meio de "conquistar o paraíso economicamente" ("emporter le paradis économiquement"). O burguês que fez a ação de certa forma justifica-se dizendo que nada dá mais prazer do que "surpreender um homem dandolhe mais do que ele espera" ("surprendre un homme en lui donnant plus qu'il n'espère"). Nesta cena teatral, Baudelaire não apenas encena a própria linguagem, com a sua hierarquia de palavras "pobres" e "ricas" (lembremos que o burguês antes de passar a sua esmola falsa realiza uma cuidadosa triagem de suas moedas distribuindo-as em diferentes bolsos), mas também podemos ver neste poema a apresentação da própria atividade do poeta que com uma moeda prosaica pode dar início a uma Fortuna poética.

A cena toda é um poema. De certa maneira ao ler boa literatura o leitor sempre se surpreende com a dádiva poética que vai além do que poderíamos esperar. Mais do que um duplo da realidade, o poema cria uma realidade, a saber uma cena onde dois burgueses "sofisticados" se diferenciam de um mendigo. A "sofisticação" dos burgueses é estabelecida tanto pela capacidade de desprendimento das regras morais, como por um certo tom de superioridade dos dois caminhantes na sua total (in)diferença com relação ao mendigo (que não tem voz e é descrito apenas como alguém que treme e possui "yeux suppliants"), como também pelo discurso moral encadeado pelo narrador. É como se ocorresse aqui uma divisão de tarefas modelar: um burguês, que se coloca como um "homme sensible" encarna as instituições da ordem, como a Religião, o Estado e seu braço jurídico, e o outro concretiza a imagem do burguês como aquele que pode se colocar acima das leis que ele mesmo cria. Neste personagem podemos ver a estrutura soberana do poder, que coloca aquele que cria as leis como estando fora e acima delas. Esta figura é complementada pela imagem do mendigo como aquele que habita uma margem enfeitiçada, onde ele pode ser tanto uma vítima do rigor das leis (ele corre perigo de ir para a prisão), como também é aproximado de um animal, mais especificamente de um cachorro espancado. Este mendigo-animal pode ser lido, hoje, como uma figuração daquele que Agamben denominou de homo sacer, ou ainda, inspirado em Walter Benjamin, da "vida nua", um ser que é excluído do círculo da cidadania e da política, como que garantindo assim uma margem, um contorno que abriga e determina dialeticamente os dois burgueses de nossa história.

O parágrafo final do poema trata da condenação do ato de dar uma moeda falsa. O, digamos, "bom burguês", diz que quase perdoaria o que ele denomina de "criminoso prazer" ("criminelle juissance"), mas não poderia perdoar a "inépcia do cálculo" ("ineptie de son calcul”). Para ele, o vício mais irreparável é fazer o mal por meio da besteira. Mas para o leitor nada é certo: seria realmente o "burguês malvado" tão ignorante e inocente das consequências de sua ação? A fala desse personagem indica que ele julgava que estava simplesmente tornando aquele mendigo feliz, surpreendendo-o, "dando-lhe mais do que ele espera" ("en lui donnant plus qu'il n'espére"). Este mendigo, que se considerava uma espécie de grau zero da humanidade, não esperaria ser tão "valorizado" por um burguês "distinto" - que na verdade o está ludibriando. Mas e se as palavras desse burguês forem apenas meias verdades? E se ele for capaz de passar "fausses paroles" assim como o era de passar "fausses monnaies"? Do ponto de vista do "bom burguês", esse homem que é considerado "perverso" ("méchant"), também está em dívida, na medida em que não pode ser perdoado. Sua condição é caracterizada tanto pela sua infinita capacidade de passar moedas falsas, como também pelo fato de ele nunca poder ser perdoado. Vemos neste poema, na verdade, mais uma das muitas manifestações da estrutura em círculo vicioso que caracteriza esse volume de poemas em prosa de Baudelaire no qual ele se encontra, Le spleen de Paris (1869). É como se a poesia se apresentasse como um sistema fechado, autopoético, mas que ao mesmo tempo se mostra como um microcosmo do mundo a sua volta. Assim, o campo estético ressignifica o mundo "real" descrevendo-o de outro modo e deslocando-o.

Neste sentido, os poemas literalizam a forma "poema em prosa" que os marca. No livro podemos ler as características desta nova sociedade capitalista que mais tarde, em 1921, Walter Benjamin dissecou em seu fragmento "Kapitalismus als Religion" ("Capitalismo como religião"). Aí Benjamin descreveu o que seriam as quatro características principais do capitalismo como religião: trata-se de uma religião apenas com culto (e que não tem nenhuma dogmática nem uma teologia); em segundo lugar este culto é sem fim e sem limite; em terceiro, este culto é caracterizado por nos endividar. Tudo gira em torno da Schuld, termo, como sabemos, amplamente explorado na sua ambiguidade por Nietzsche, tanto no seu sentido de culpa como no de dívida. Temos sempre 
uma culpa/dívida impagável. Por fim, o capitalismo como religião é marcado para Benjamin pelo ocultamento de Deus (BENJAMIN, 1985, p. 100s.). Nesse fragmento, Benjamin ainda especula sobre as semelhanças entre as notas de dinheiro e as imagens de santos (tema que ele aborda também no seu Einbahnstrasse [Rua de mão única]) e nota que o capitalismo se desenvolveu no ocidente de modo parasitário ao Cristianismo, tomando dele seus elementos míticos (BENJAMIN, 1985. p. 102). "La fausse monnaie" pode ser lido como uma alegoria desta força mítica do capitalismo que revela ao mesmo tempo suas raízes cristãs.

E mais: com este poema em prosa vemos uma paradigmática intersecção do mundo da prosa da vida (econômica) com a esfera estética. Baudelaire escreveu na dedicatória a Arsène Houssaye do volume Le spleen de Paris, que serve de introdução ao volume, que "É sobretudo da frequentação das cidades enormes, do cruzamento de suas inumeráveis relações, que nasce a obsessão desse ideal" (BAUDELAIRE, 1937, p. 5). ("C'est surtout de la fréquentation des villes énormes, c'est du croisement de leurs innombrables rapports que naît cet idéal obsédant" [BAUDELAIRE, 1975, p. 276]). O gênero poème en prose, que é o tema da introdução e de muitos dos poemas em prosa do volume, é apresentado como um fruto da modernidade e das grandes cidades. Baudelaire declara que procura neste volume a "descrição da vida moderna, ou antes, de uma vida moderna e mais abstrata" (BAUDELAIRE, 1937, p. 5) ("la description de la vie moderne, ou plutôt d'une vie moderne et plus abstraite" [BAUDELAIRE, 1975, p. 275]). A prosa da Modernidade é ao mesmo tempo a fonte e o tema dos poemas. Em "La fausse monnaie" podemos ler também uma espécie de prefiguração do desaparecimento do homo laborans e do nascimento de duas novas espécies que se tornaram pedras de toque do nosso mundo: o homo aestheticus e o homo sacer. O primeiro incorpora muitos aspectos daquilo que foi sonhado para o novo homem desde o final do século XVIII por pensadores, como os membros do romantismo alemão Friedrich Schlegel e Novalis. Para eles, o artista estaria no topo da humanidade. A arte curaria as feridas abertas pelo progresso e pela alienação que caracteriza o indivíduo moderno. Por outro lado, o homo sacer é pensado, segundo Agamben, como um resto, uma descarga em forma de carne humana que é rejeitada pela sociedade como meio de se manter a estrutura de poder do soberano. Essa paisagem biopolítica não é estática e tem a sua própria dinâmica. Podemos dizer que um lado da moeda depende da existência do outro lado. $\mathrm{O}$ espetáculo da violência, pobreza e miséria é parte de nosso mundo estetizado e não o seu oposto. Nesse sentido, o poema é uma espécie de microcosmo de nosso mundo e de sua nova moneyscape.
Mais do que isto, a ideia de uma "falsa moeda" que pode estar na origem de riquezas efêmeras ou infindas, remete a um potencial tendencialmente infinito de enriquecimento tanto da sociedade capitalista como também da "fortuna poética", ou seja, do campo estético e do valor das obras. O capitalismo baseia-se em um sistema monetário e de criação de valores que está longe de ter uma base sólida, como a crise global de outubro de 2008 o mostrou. Seus pés são de barro, mas sua lógica de crescimento exponencial até agora não foi abandonada, mesmo com as grandes crises financeiras. Nesse sistema capitalista, calcado no utilitarismo e no fetichismo da mercadoria, o artista ocupa um local ambíguo. Por um lado, como aquele que não produz nada de útil, o artista desde o romantismo está à margem da sociedade. De certa forma o romance de formação encena a passagem deste artista por uma metamorfose que culmina no seu enquadramento na sociedade burguesa - ou, outras vezes, no fracasso deste enquadramento e em seu desterro ou morte. Por outro lado, o artista muitas vezes ainda ocupa um lugar de destaque na economia simbólica das sociedades modernas e na verdade vem aumentando seu capital simbólico cada vez mais. Suas obras podem atingir cifras astronômicas de dezenas de milhões de dólares. Lembro que a obra de Damien Hirst, paradigmaticamente denominada de "For the love of God" (2007) - puro capitalismo como religião e encenação estética - foi posta a venda por 50 milhões de libras.

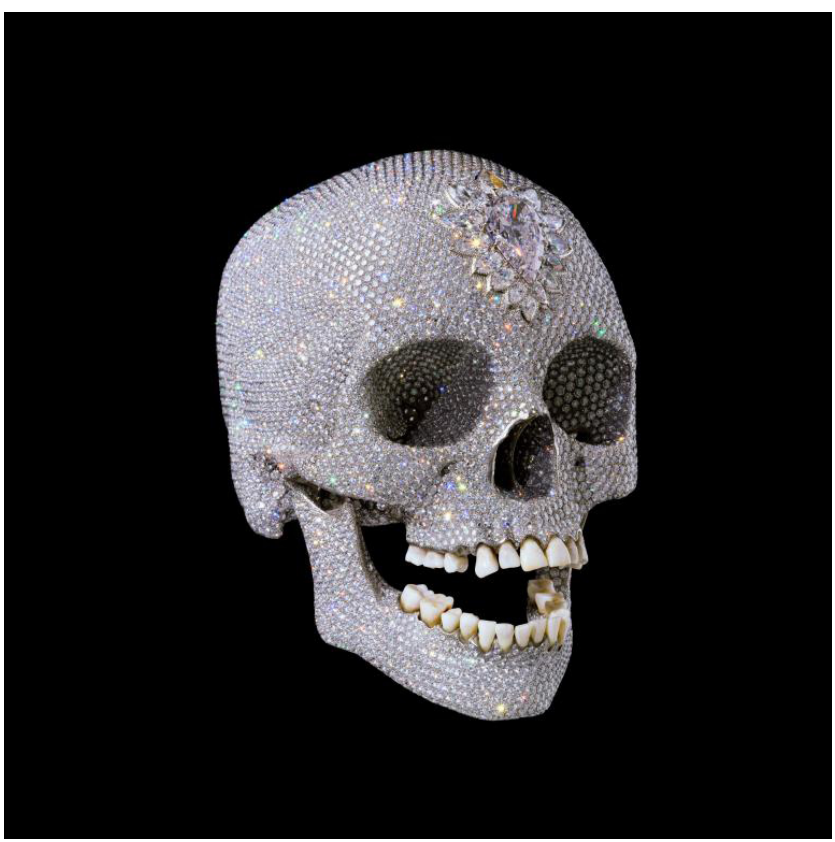

Figura 1. "For the Love of God". Artista: Damien Hirst (2007).

Ela consiste em uma cópia em platina de um crânio humano do século XVIII, com 8.601 diamantes 
incrustados, sendo que os dentes são humanos ${ }^{1}$. Andy Warhol com seu "192 One Dollar Bills" de 1962 iniciou uma série de obras nas quais tematizava a relação entre arte, especulação financeira, culto das estrelas e também a violência e a morte.

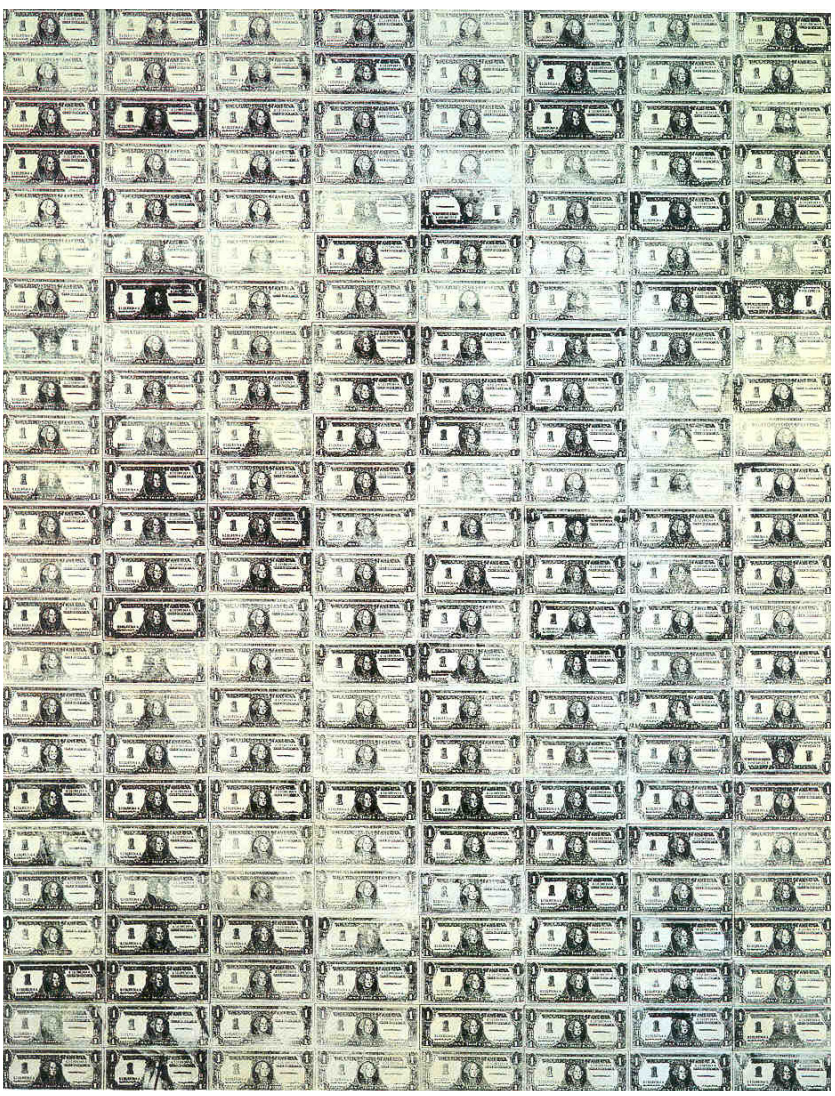

Figura 2. "192 One Dollar Bills". Artista: Andy Warhol (1962).

Neste sentido, vale pensar que se Benjamin estabeleceu um paralelo entre o capitalismo e a religião, o mesmo vale para a relação deste sistema com o campo estético. Estamos diante de uma gritante permeabilidade entre o capitalismo, a religião e as artes. Estas últimas servem de reflexo e local de ensaio para as aventuras mais arriscadas dos capitalistas. O capitalista-Midas vê no artista-Midas uma espécie de irmão rebelde, mais

\footnotetext{
Com relação a esta obra vale lembrar os versos de Ricardo III de Shakespeare (I.4.23-33), memorável antecipação iconográfica do trabalho de Hirst:

Methoughts I saw a thousand fearful wrecks,

A thousand men that fishes gnaw'd upon,

Wedges of gold, great anchors, heaps of pearl,

Inestimable stones, unvalued jewels,

All scatt'red in the bottom of the sea;

Some lay in dead men's skulls, and in the holes

Where eyes did once inhabit there were crept,

As 'twere in scorn of eyes, reflecting gems,

That woo'd the slimy bottom of the deep

And mock'd the dead bones that lay scatt'red by.
}

ousado e que conseguiu levar as artes de Midas às suas últimas consequências. Se Benjamin notou que os valores de culto e de exposição nas obras e arte relacionavam-se de modo inverso, quanto maior o valor de exposição, menor o de culto, e vice-versa - por outro lado, ele não levou em conta o crescimento do valor monetário das obras de arte derivado de sua exposição crescente. $\mathrm{O}$ fato de que hoje em dia obras de arte são vendidas por somas astronômicas apenas indica esse espaço ambíguo que as obras e arte ocupam na nossa cultura: elas não têm, literalmente, valor algum, o que significa que podemos projetar qualquer valor nelas. O sistema arte não apenas serviu como um modelo de autorreflexão para o homem moderno e pós-romântico, mas também de autorreflexão para o próprio sistema capitalista, que se tornou mais e mais em algo como um grande jogo especulativo sem bases sólidas. Se no campo da economia existe uma angústia constante quando se trata de enfrentar o futuro (o tempo na economia se tornou deformado, como ele o é para o jogador: é o tempo de agora do acaso), por outro lado, aprendemos com as artes a projetar imagens nas quais projetamos um futuro que nos consola. $\mathrm{O}$ artista e suas obras são considerados agora como janelas através das quais podemos ver o futuro da humanidade.

No campo das artes não podemos mais separar o papel das grandes exposições, como a Documenta e as Bienais, das grandes Feiras de arte, do trabalho das poderosas casas de leilão como a Sothebys e a Christies e ainda da ação dos próprios críticos e teóricos da arte. É neste sistema que a arte existe hoje e recusar isto é simplesmente recusar a realidade. Andy Warhol soube capitalizar - literalmente, ainda uma vez - em cima deste fato, trazendo para suas obras e para sua performance artística esta consciência com relação a essa pertença aos campos tanto do mercado como do religioso, nessa nova religião que é puro culto, carregada por aquilo que Benjamin denominou certa vez nas notas do seu Passagen-Werk de "sex appeal do anorgânico". As palavras de Benjamin com relação à moda são fundamentais neste contexto: "A moda abre o ponto de transbordo dialético entre a mulher e a mercadoria entre o prazer e o cadáver. [...] a moda nunca foi outra coisa, senão a paródia do cadáver colorido, provocação da morte por meio da mulher e, entre risos estridentes memoráveis, uma conversa amarga sussurrada com a decomposição. Isto é a moda. Daí ela mudar com tanta velocidade" (BENJAMIN, 1982, p. 111). Leia-se ainda destas mesmas notas: a moda "engata o corpo (Leib) vivo ao mundo anorgânico. A moda percebe nos viventes os direitos do cadáver. $\mathrm{O}$ fetichismo, submetido ao sex appeal do anorgânico, é o seu nervo vital" (BENJAMIN, 1982, p. 130). A moda concentra em si uma dialética que remete às tensões entre a libido e a pulsão de morte. Nela, sexo e morte se encontram, como uma espécie de 
absoluto. Warhol trouxe essa força da moda para dentro de suas obras revelando nelas o culto do dinheiro e o estético como o campo par excellence da especulação. Esse artista assim, ironicamente, serviu de vanguarda ao capitalismo especulativo contemporâneo.

$\mathrm{O}$ artista e sua obra como meios de vislumbrar o futuro faz pensar tanto no potencial das artes de virtualizar o que está por vir, como também nos faz recordar da tradição neo-platônica que projetava nos artistas a capacidade de observar o mundo das ideias. Se os artistas eram considerados como aqueles que eram capazes de dar forma palpável aos arquétipos, às ideias, ou à origem daquilo que existiria de modo derivado na terra, agora, por outro lado, tendemos a ver no campo das artes a antecâmara do futuro. $\mathrm{O}$ artista é visto como um profeta. Ele o é tanto pela sua capacidade de jogar e especular com valores (simbólicos e monetários), como também por sua capacidade de entender a técnica como uma extensão do nosso corpo. Algo de demiúrgico é projetado no artista, como vemos desde o Frankenstein de Mary Shelley e do Faust de Goethe. A força fáustica do homem moderno é ao mesmo tempo uma pulsão estética, técnica e monetária. Esta tríade compõe a nova trindade do capitalismo como religião, que se organiza em torno do culto da mercadoria e do dinheiro. Este culto, como vimos com Benjamin, nos endivida/culpabiliza e leva apenas a mais culto. $\mathrm{O}$ artista é esta figura que, como no poema de Baudelaire, está aquém e além da moral. Ele é, antes de mais nada, aquele que transgride.

Nesse sentido, é importante marcar novamente a ambiguidade de "La fausse monnaie", a sua profunda e aberta ironia. Não por acaso inicialmente Baudelaire batizou este poema em prosa com o título "Le Paradoxe de l'aumône". Tudo no Spleen de Paris gira em torno do paradoxo, do oximoro. Aliás essa mesma estrutura paradoxal já se encontra na passagem do texto L'école païenne que está na origem de "La fausse monnaie". Lá, Baudelaire narra que de fato conheceu um artista que ao receber uma moeda falsa disse que a reservaria para um pobre ("pour un pauvre"; BAUDELAIRE, 1976, p. 49). O comentário de Baudelaire deixa claro como ele se identifica com o narrador do poema em prosa que depois ele escreveu: "O miserável tinha um prazer infernal em roubar do pobre e em gozar ao mesmo tempo os benefícios de uma reputação de caridade" ("Le misérable prenait un infernal plaisir à voler le pauvre et à jouir en même temps des bénéfices d'une réputation de charité" [BAUDELAIRE, 1976, p. 49]). Ou seja, o artista é descrito como alguém sem moral que apostava na sua aparência, a reputação de caridoso, ao mesmo tempo que fazia mal ao pobre. Mas ao deslocar esta cena para dentro de seu livro de poemas em prosa, o que parecia uma dicotomia banal - ou seja, a oposição entre uma atitude moral e outra imoral, a união entre um gozo e uma falsa aparência - tem sua estrutura como que dissolvida. Como vimos, a condenação final daquele que passou a falsa moeda é feita não pela ação em si, que o narrador estaria pronto a perdoar, mas pela ignorância do autor da ação. Esta ignorância, no entanto, também pode ser pura simulação. Neste sentido poderíamos pensar também se a nossa sociedade também não simularia não perceber que ao passar a falsa moeda da caridade para seus pobres apenas reforça um sistema que se multiplica justamente ampliando a diferença entre os ricos e os pobres. A janela do estético permite a Baudelaire "simular" esta hipocrisia da nossa sociedade - que nos é tão cara. O caráter "fake" do campo estético permite uma desconstrução das dicotomias e polaridades, como Baudelaire mostra de modo brilhante no seu Le spleen de Paris.

Mas para concluir este pequeno périplo pelas potencialidades das artes hoje, gostaria de insistir mais na questão por assim dizer "moral" tocada pelo poema de Baudelaire. $\mathrm{O}$ narrador parece portar ideias rígidas com relação ao modo como devemos lidar com o dinheiro. $\mathrm{Na}$ história cultural ocidental ao lado de representações da boa fortuna e da bela e graciosa Abundância com sua cornucópia, indicando a riqueza e a felicidade, encontramos uma vasta tradição, desde a Antiguidade, na qual se prega um comedimento e uma moral no trato com o dinheiro.

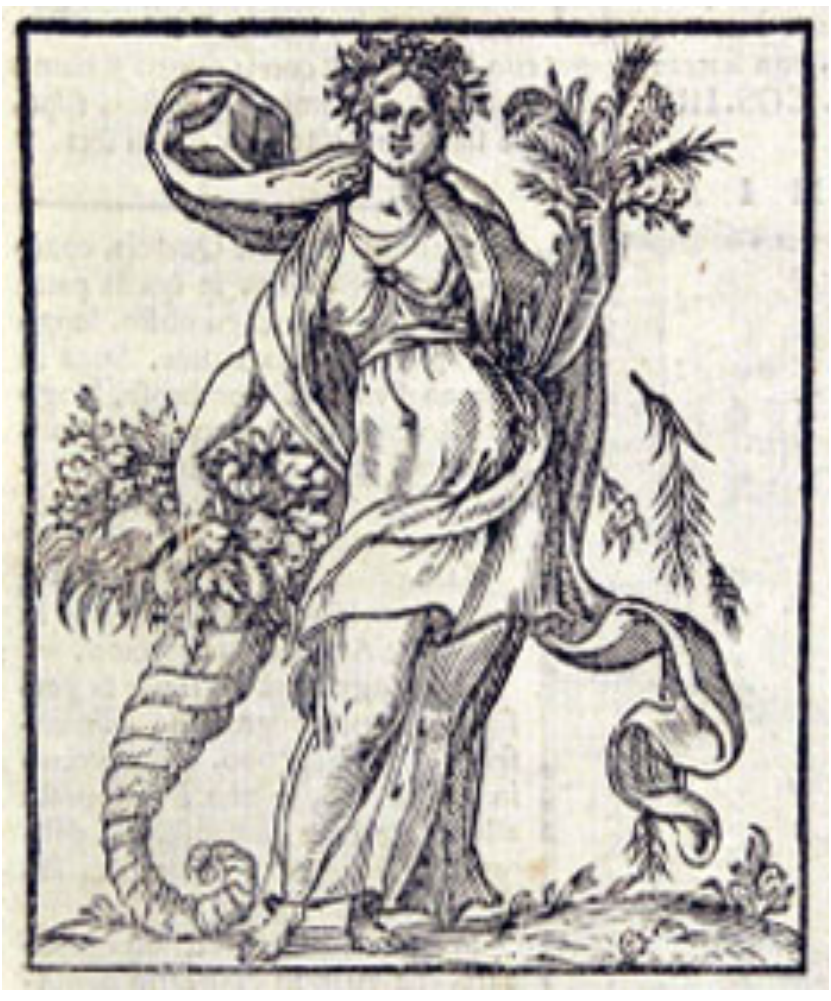

Imagem 3. "Allegoria dell'Abbondanza", Iconologia. Artista: Cesare Ripa (1603). 
O referido mito de Midas em Ovídio também apresenta um personagem ganancioso que é retratado como burro (e inclusive recebe de Apolo orelhas de asno). Midas é caracterizado por Ovídio como "rico e pobre" e quase morre de fome por seu desejo singular, uma "desastrosa dádiva", como escreve Ovídio, de modo oximoresco, como depois Baudelaire caracterizaria seu personagem de "La fausse monnaie". Da Antiguidade - e posteriormente adotada pelo cristianismo - vem também a tradição de se representar a avareza como um dos sete pecados capitais, ao lado da gula, da melancolia/preguiça, da inveja, da ira, da luxúria e do orgulho/vaidade. Mammon neste sentido é uma figura paradigmática no cristianismo, que é vista como aquele que encarna o lado diabólico do apego ao dinheiro. Não é acaso se ele também foi visto como um deus falso (uma outra versão do cordeiro de ouro bíblico), ou como um (dis)simulador, como no mundo cristão também muitas vezes se condenavam os artistas, especialmente os atores, como dissimuladores. (Deixo de lado aqui a longa tradição antissemita que sempre procurou atribuir aos judeus o culto do falso deus Mammon, da Idade Média aos Protocolos dos sábios do Sião, até nossos dias. Seria interessante enfrentar a questão da profunda relação do judaísmo não com Mammon, mas sim com as artes no século XX e com o campo estético de um modo geral. Mas deixo este tema para outra ocasião.)

No Renascimento, dentro do espírito do humanismo, muitos artistas representaram esta associação entre avareza e o mal. A arte funciona nestes casos como um dispositivo mnemônico da paidéia que serve para recordar as virtudes e admoestar contra os vícios. A avaritia é representada muitas vezes como uma velha feia e melancólica, acompanhada de um lobo magro, um animal "ávido e voraz", como lemos na Iconologia de Cesare Ripa, citando neste ponto a Christofano Landino.

Com o romantismo, no entanto, este movimento das artes em direção à moralização, que havia se mantido até o Iluminismo, entrou em colapso. Mais e mais as artes passaram justamente a ser um dispositivo para se apresentar aquilo que havia sido censurado, recalcado e proibido de se manifestar, aquilo que depois Freud denominou, inspirado em Schelling, de Unheimlich. O artista se torna, como vimos acima, esta figura que coloca em suspensão os valores de um modo geral: em termos morais e monetários. A potencialidade das artes nunca foi tão ampla quanto nos dias de hoje. Nunca ela esteve tão próxima das ciências e da política. É verdade que se Benjamin viu na estetização da política um traço fascista, hoje nada garante que estamos a salvo do fascismo. $\mathrm{O}$ artista-demiurgo pode tanto estar a serviço de novos

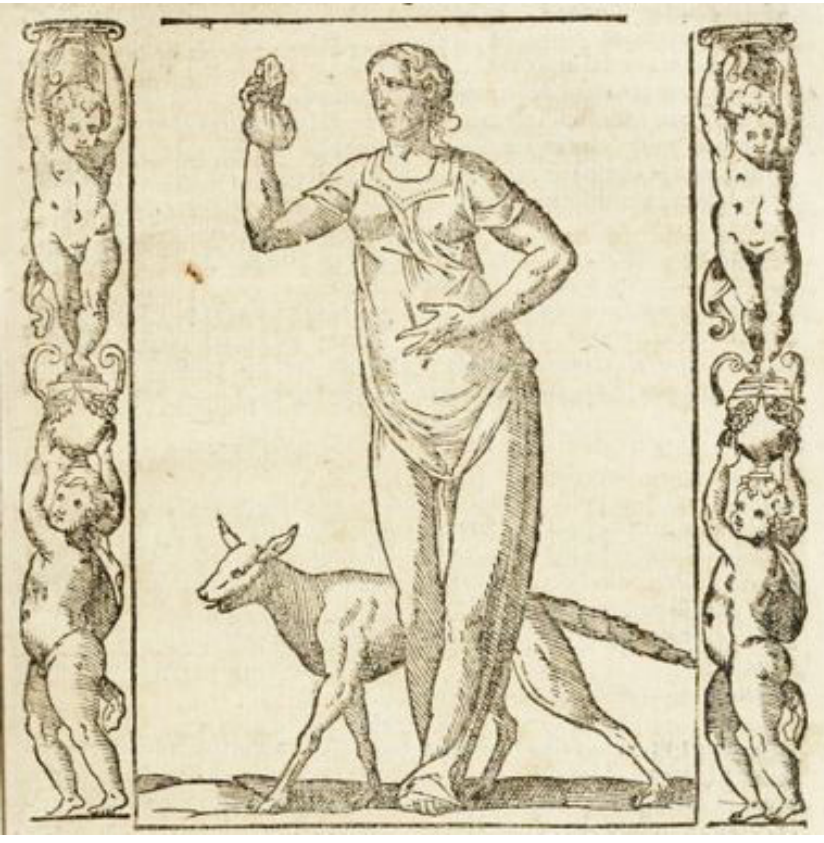

Figura 4. "Avaritia", Iconologia. Artista: Cesare Ripa (1603).

programas ontotipológicos - auxiliando no design de um novo homem que significaria a morte e/ou o extermínio dos que ficam de fora desta categoria - como também pode, criticamente, servir à Gestaltung de um mundo plástico, onde os indivíduos teriam espaço livre para desdobrar as suas diferenças e contradições. Como Pascal aconselhava no século XVII a apostar na existência de Deus, acho defensável apostar, hoje, na possibilidade deste desfecho positivo para as criações deste homo aestheticus. Tudo vai depender de nossa capacidade de conseguir incluir o homo sacer em nossas vidas de modo a integrá-lo não mais como resto, mas como um igual.

\section{Referências}

BAUDELAIRE, Charles. Oeuvres completes. Paris: Gallimard, 1975.

BAUDELAIRE, Charles. Euvres complétes. Paris: Gallimard, 1976.

BAUDELAIRE, Charles. Pequenos poemas em prosa. Rio de Janeiro: Athena Editora, 1937.

BENJAMIN, Walter. Gesammelte Schriften. Das PassagenWerk. Frankfurt a.M.: Suhrkamp, 1982.

BENJAMIN, Walter. Kapitalismus als Religion. Gesammelte Schriften. Fragmente vermischten Inhalts. Autobiographische Schriften. Frankfurt a.M.: Suhrkamp, 1985. p. 100-103.

Recebido: 21 de julho de 2015

Aprovado: 30 de agosto de 2015

Contato: marcioseligmann@me.com 